\title{
Old Drawback on Azlactone Formation Revealed by a Combination of Theoretical and Experimental Studies
}

\author{
Pedro P. de Castro, ${ }^{a}$ Gabriel M. F. Batista, ${ }^{a}$ Danielle L. J. Pinheiro, ${ }^{a}$ \\ Hélio F. dos Santos $*$,a and Giovanni W. Amarante A,a $^{*}$ \\ ${ }^{a}$ Departamento de Química, Universidade Federal de Juiz de Fora, Campus Martelos, \\ 36036-900 Juiz de Fora-MG, Brazil
}

\begin{abstract}
New insights into the formation of azlactone heterocycles bearing different substituents are hereby presented. The sum of both kinetic and thermodynamic factors contributes for the formation of 2-alkyl or 2-aryl substituted azlactones, while the cyclization of 2-alcoxy azlactones is less favored. These results are in perfect accordance with experimental observations obtained by infrared (IR) and electrospray ionization mass spectrometry (ESI(+)-MS) of the crude reaction mixture.
\end{abstract}

Keywords: azlactone, oxazolone, DFT

\section{Introduction}

Over the last years the development of efficient reactions for the preparation of complex biologically active amino acid derivatives has been a major area in organic chemistry. ${ }^{1}$ In this context, azlactones (also known as oxazolones) are versatile building blocks with several uses in organic synthesis. ${ }^{2}$ This is mainly due to the fact that after one or few reaction steps, the molecular complexity of the compounds can be greatly enhanced. ${ }^{3}$ Besides, these heterocycles have both pro-nucleophilic and electrophilic sites in their scaffold, allowing their use in different types of transformations. ${ }^{4}$

Although in some cases the formation of 2-alcoxy azlactones (formed by the cyclization of amino acids protected by a carbamate group) has been described, ${ }^{5}$ the majority of the reports employ 2-aryl or 2-alkyl substituted oxazolones (Scheme 1). Furthermore, in the few reports concerning 2-alcoxy azlactones, the isolated yields were often poor. ${ }^{6}$ It is worth mentioning that these azlactones are sometimes observed as minor by-products during peptide coupling. ${ }^{7}$ Our research group ${ }^{8-14}$ has been studying several chemical transformations employing azlactone rings over the last years and we were recently interested in the formation and reactivity of unusual oxazolones, such as the 2-alcoxy azlactones. ${ }^{15}$ In this context, we herein present an integrated theoretical and experimental investigation concerning the formation of different 2-substituted azlactones.

*e-mail: helio.santos@ufjf.edu.br; giovanni.amarante@ufjf.edu.br

\section{Results and Discussion}

Despite the previous reports concerning the formation of the 2-alcoxy substituted azlactones, ${ }^{5,6}$ we found out that their preparation and isolation is harsh. In an attempt to better comprehend this problem, we decided to evaluate theoretically its preparation and compare the data with the most commonly employed azlactones. Thus, hereby we present a computational study, based on experimental evidences, to explain the formation of these heterocycles at molecular level.

It is well known that azlactone formation consists in a two-steps tandem reaction. Initially, the $\mathrm{N}$-protected amino acid should be activated by a carboxylic acid activator (Figure 1); herein, the commercially available 1-ethyl-3-(3-dimethylaminopropyl)carbodiimide (EDC) was employed. It is possible to observe in Figure 1 that the substituent has a little effect in the overall energies for the first step. The TS1 (transition state 1) consists in a 6-membered ring arrangement (Figure 2a), in which both the oxygen-carbon bond formation and the hydrogen transfer occur simultaneously.

Some important intramolecular interactions could be observed during this reaction. The interactions in molecular complex of the reagents (MC1), TS1 and initial conformation for the activated amino acid (C1) show considerable differences in $\mathrm{N}^{1}-\mathrm{H}^{1}$ bond lengths $(1.78,1.09$ and $1.01 \AA$, respectively), due to the hydrogen transfer from the carboxylic acid to the carbodiimide moiety, and in the $\mathrm{C}^{1}-\mathrm{O}^{2}$ bond length $(3.39,2.17$ and $1.41 \AA$, respectively), 


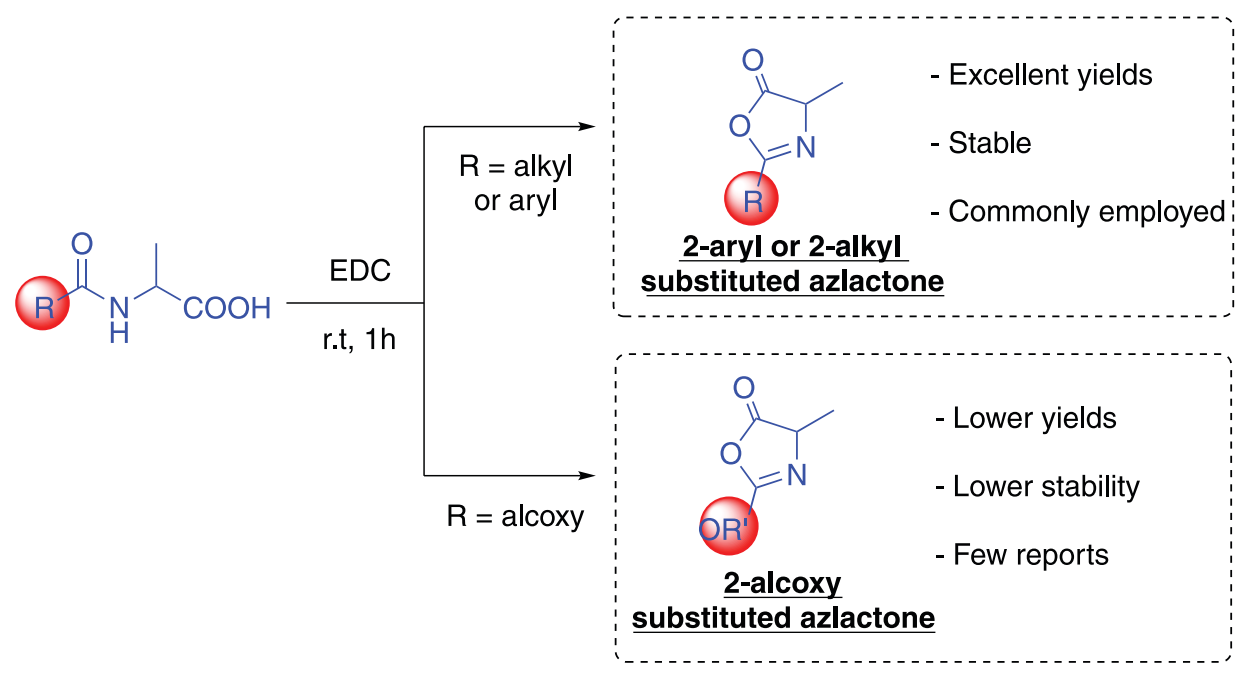

Scheme 1. Preparation of 2-substituted azlactones.

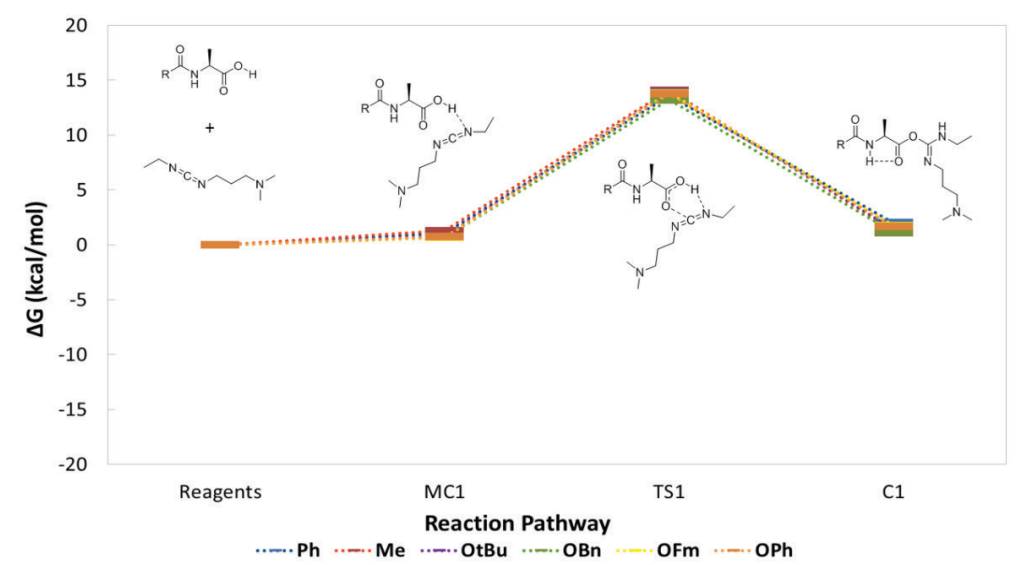

Figure 1. Reaction pathway in dichloromethane calculated at PBE0-D3/6-31++G(d,p)//B3LYP/6-31G(d) level of theory for the amino acid activation by EDC. MC1: molecular complex 1; TS1: transition state 1; C1: activated amino acid, conformation 1 .

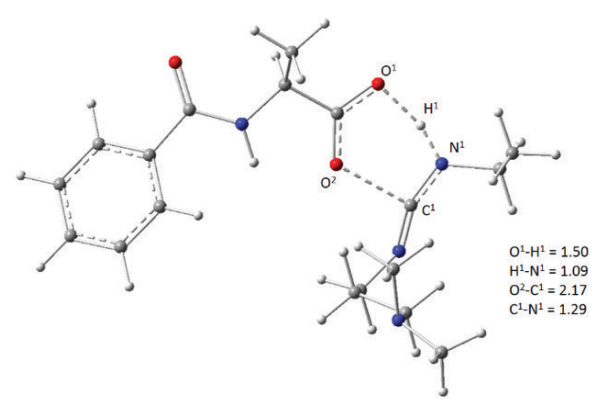

(a) TS1

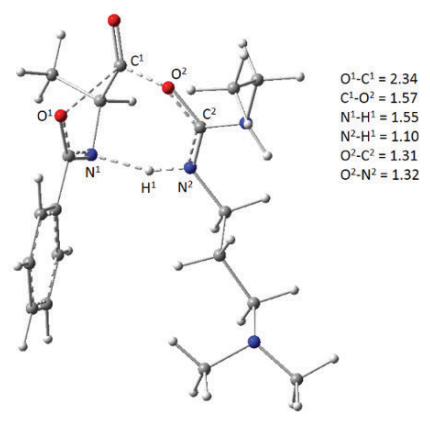

(b) TS2

Figure 2. Important geometrical features of the transition-states for the amino acid activation by EDC (a, TS1) and for the cyclization step (b, TS2). Distances are given in $\AA$.

with formation of the activated amino acid product. This first step results in the formation of an activated amino acid intermediate in an extended conformation (C1). This conformer changes to a more stable structure $(\mathrm{C} 2)$ in which an intramolecular hydrogen bond is formed in the EDC moiety. Moreover, another interesting aspect of this reaction is that for the activated amino acid species to proceed into the cyclization step it must turn to a folded conformation (C3) (Figure 3).

These three conformers show considerable differences in the intramolecular contacts: $\mathrm{C} 1$ shows a hydrogen bond between the amide hydrogen and the oxygen of the amino 


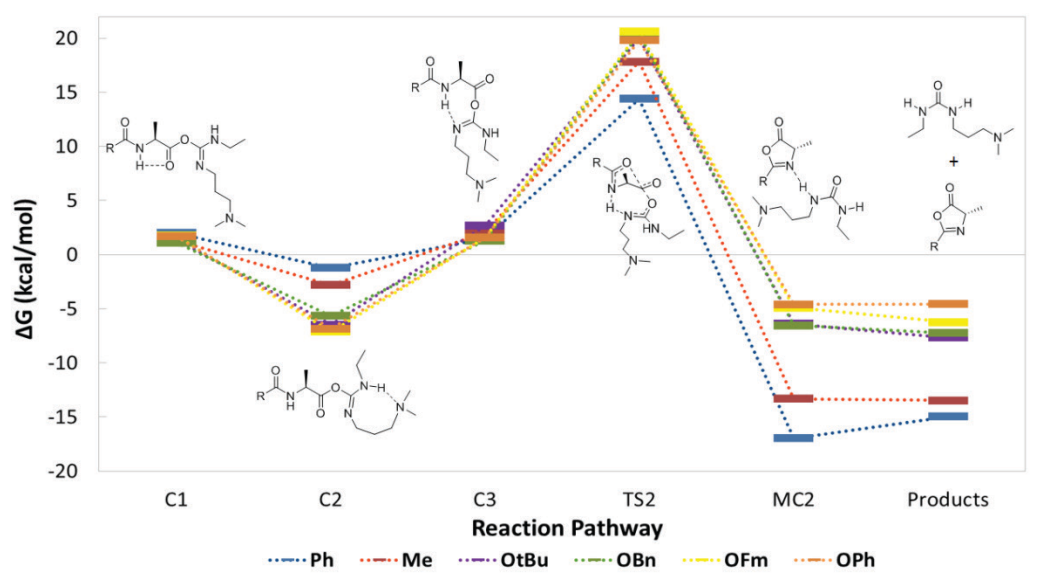

Figure 3. Reaction pathway for the second step of azlactone formation at dichloromethane and PBE0-D3/6-31++G(d,p)//B3LYP/6-31G(d) level of theory. C1-C3: conformers; TS2: transition state 2; MC2: molecular complex 2.

acid moiety (an $\mathrm{O} \cdots \mathrm{H}$ distance length of $2.18 \AA$, Wiberg bond index $(\mathrm{W})=0.0140)$, in a 5-membered ring moiety; in $\mathrm{C} 2$ no such interaction exists, with a hydrogen bond between the tertiary amine of the EDC moiety and the $\mathrm{N}-\mathrm{H}$ group of the carbodiimide scaffold (an $\mathrm{N} \cdots \mathrm{H}$ distance of $2.04 \AA, \mathrm{W}=0.0564)$, resulting in an 8-membered ring arrangement; finally, in $\mathrm{C} 3$ the hydrogen bond occurs between the amide hydrogen and the carbodiimide nitrogen atom (in a 7-membered ring moiety with $\mathrm{N} \cdots \mathrm{H}$ distance of $2.32 \AA, \mathrm{W}=0.0171$ ). The conformational interconversions of the three conformers involve torsions around several bonds simultaneously and could not be traced precisely. The main torsion for $\mathrm{C} 1 \rightarrow \mathrm{C} 2$ consists in changes in the $\mathrm{N}-\mathrm{C}-\mathrm{C}-\mathrm{N}$ dihedral (EDC moiety) and for $\mathrm{C} 2 \rightarrow \mathrm{C} 3$ interconversion in the $\mathrm{N}-\mathrm{C}-\mathrm{C}-\mathrm{O}$ dihedral (amino acid moiety).

Following the conformational interconversions, an intramolecular cyclization occurs, yielding the azlactone and with formation of EDC urea as a by-product (Figure 3). In this case, both the cyclization and the hydrogen transfer between nitrogen atoms occur simultaneously. This reaction step can be clearly followed by the changes in bond lengths during the cyclization step by analyzing C3, TS2 (transition state 2) (Figure 2b) and MC2 (molecular complex 2), in this order; with a hydrogen transfer between nitrogen atoms (bond lengths $\mathrm{N}^{1}-\mathrm{H}^{1}-\mathrm{N}^{2}$ of 1.01/2.32, 1.55/1.10, and 2.09/1.02 $\AA$, respectively) and carbon-oxygen bond formation and cleavage $\left(\mathrm{O}^{2}-\mathrm{C}^{1}-\mathrm{O}^{1}\right.$ bond lengths of $1.39 / 2.93,1.57 / 2.34$, and 4.3/1.4 ̊̊, respectively).

An overview of the potential energy surface for the second reaction step is summarized in Figure 3. Although the activated amino acid intermediate has preference for the most stable conformation (C2) in all cases, in the carbamate derivatives it is great stabilized (6.8 to $9.1 \mathrm{kcal} \mathrm{mol}^{-1}$ more stable than $\mathrm{C} 1$ and $\mathrm{C} 3$ ). Since for the cyclization step to take place the folded conformation $\mathrm{C} 3$ must be previously attained, this conformer is easily accessed for either aryl or alkyl substituted amino acids. Furthermore, the transition state and products for the cyclization step also greatly differ in energy for the formation of 2-alkyl and 2-aryl oxazolones from the 2-alcoxy azlactones, showing that the former is favored both kinetically and thermodynamically (with both $\Delta \mathrm{G}_{\mathrm{C} 3 \rightarrow \mathrm{TS} 2}^{\ddagger}$ (Gibbs free energy variation between TS2 and C3) for the cyclization step 1.6-5.3 kcal mol-1 lower and an overall reaction $\Delta \mathrm{G}_{\mathrm{C} 3 \rightarrow \mathrm{MC} 2}$ (Gibbs free energy variation between MC2 and C3) 6.3-12.2 kcal mol ${ }^{-1}$ lower than when using carbamate protected amino acids). This explains why these azlactones can be easy prepared and are widely employed in the literature, while examples concerning the 2-alcoxy azlactones are sparse. It is worth mentioning that this cyclization step is the rate-limiting step for the overall reaction. Another interesting finding is the fact that the 2-phenyl oxazolone is slightly more stable when compared to the 2-methyl substituted analogue, probably due to additional stabilization of the product by electron conjugation with the aryl group (our group experience with 2-methyl-substituted azlactones shows that these cycles are more difficult to prepared and provide lower yields than the 2-phenyl oxazolones).

In an attempt to better understand the reasons for the differences in 2-aryl and 2-alcoxy azlactones, we performed a comparison of the C2 and TS2 structures for both pathways. We found out that apparently the energy difference in both cases are due the dispersion interactions. In the $\mathrm{C} 2$ conformer, when $\mathrm{R}=\mathrm{Ph}$ (Figure $4 \mathrm{a}$ ), the structural optimizations result in a more extended conformation than when $\mathrm{R}=\mathrm{O} t \mathrm{Bu}$ (Figure $4 \mathrm{~b}$ ), in which the molecule adopts a slightly folded conformation allowing alkyl-alkyl interactions and resulting in further stabilization. On the other hand, for the TS2 structures, the opposite behavior occurs: when $\mathrm{R}=\mathrm{Ph}$ (Figure 4c), alkyl-aryl interactions are possible due to a more folded conformation than when 
$\mathrm{R}=\mathrm{O} t \mathrm{Bu}$ (Figure $4 \mathrm{~d}$ ), affording additional stabilization for 2-phenyl azlactone. A similar effect due to dispersion forces was noted for gold complexes containing bulky alkyl groups as ligands. ${ }^{16,17}$ In these previous studies, intramolecular contacts between the parallel alkyl groups contributed significantly to the structure ${ }^{16}$ and stability ${ }^{17}$ of these coordination complexes. (a)

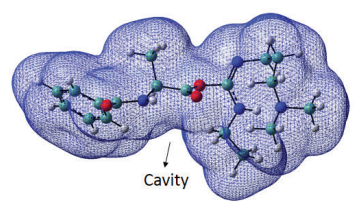

(c)

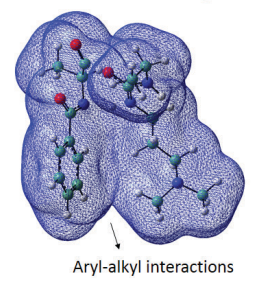

(b)

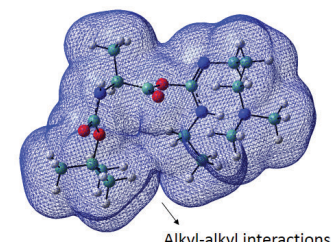

(d)

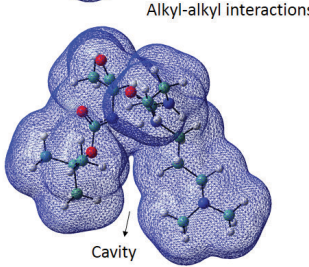

Figure 4. Comparison of structural features for reactive species in the preparation of 2-aryl or 2-alcoxy azlactones. (a) $\mathrm{C} 2$ conformer $(\mathrm{R}=\mathrm{Ph}$ ); (b) $\mathrm{C} 2$ conformer $(\mathrm{R}=\mathrm{O} t \mathrm{Bu})$; (c) TS2 $(\mathrm{R}=\mathrm{Ph})$; (d) TS2 ( $\mathrm{R}=\mathrm{O} t \mathrm{Bu})$. The meshed surface corresponds to electrostatic potential (ESP) distribution (isovalue $=0.001)$.

In the last part of the work, we decided to carry out some experiments to compare the formation of different 2 -substituted azlactones. Since the formation of the azlactone ring shows a very characteristic signal by infrared (IR) near $1800 \mathrm{~cm}^{-1}$ (lactone $\mathrm{C}=\mathrm{O}$ stretch, absent it the starting materials), it was chosen as an ideal probe to evaluate the formation of these cycles. The reaction was carried out for
$N$-protected amino acids (amino acid $=$ L-alanine) bearing both amide $(\mathrm{R}=\mathrm{Ph})$ or carbamates $(\mathrm{R}=\mathrm{O} t \mathrm{Bu}$ or $\mathrm{OPh})$ employing the classical protocol for azlactone formation (dichloromethane, r.t. for $1 \mathrm{~h}$ ); in the case of carbamates the reaction was also evaluated in dichloromethane reflux $\left(49.6^{\circ} \mathrm{C}\right)$ in an attempt to increase the azlactone formation.

The results are summarized in Figure 5 and shows that when $\mathrm{R}=\mathrm{Ph}$, the 2-phenyl azlactone is abundantly formed after $1 \mathrm{~h}$ of reaction, with an intense stretch in $1815 \mathrm{~cm}^{-1}$. On the other hand, in the case of carbamate protected amino acids, only traces of the absorption signal near $1825 \mathrm{~cm}^{-1}$ could be observed, even when increasing the temperature. The crude reaction mixture of $\mathrm{R}=\mathrm{O} t \mathrm{Bu}$ (amino acid $=\mathrm{L}$-isoleucine) was then directly analyzed by electrospray ionization mass spectrometry (ESI(+)-MS), showing an abundant ion of $\mathrm{m} / z 387[\mathrm{M}+\mathrm{H}]^{+}$corresponding to the activated amino acid and the absence of an ion corresponding to the azlactone ring. Furthermore, a low intensity ion of $m / z 467[\mathrm{M}+\mathrm{Na}]^{+}$ was also detected during the analyses (see Supplementary Information (SI) section). This ion corresponds to the anhydride formed as a minor by-product when the activated amino acid species was attacked by other $N$-protected amino acid. The anhydride group also has a $\mathrm{C}=\mathrm{O}$ stretching near $1800 \mathrm{~cm}^{-1}$ in IR, which might explain the presence of the low intensity signal in the crude IR spectra of the carbamate derivatives. This divergent behavior according to the substituent is summarized in Scheme 2. It is also worth to mention that when $\mathrm{R}=\mathrm{Ph}$ the azlactone could be easily isolated (87\% yield, see SI section). On the other hand, when $\mathrm{N}$-protected carbamates were employed as starting materials, azlactones could not be isolated and detected
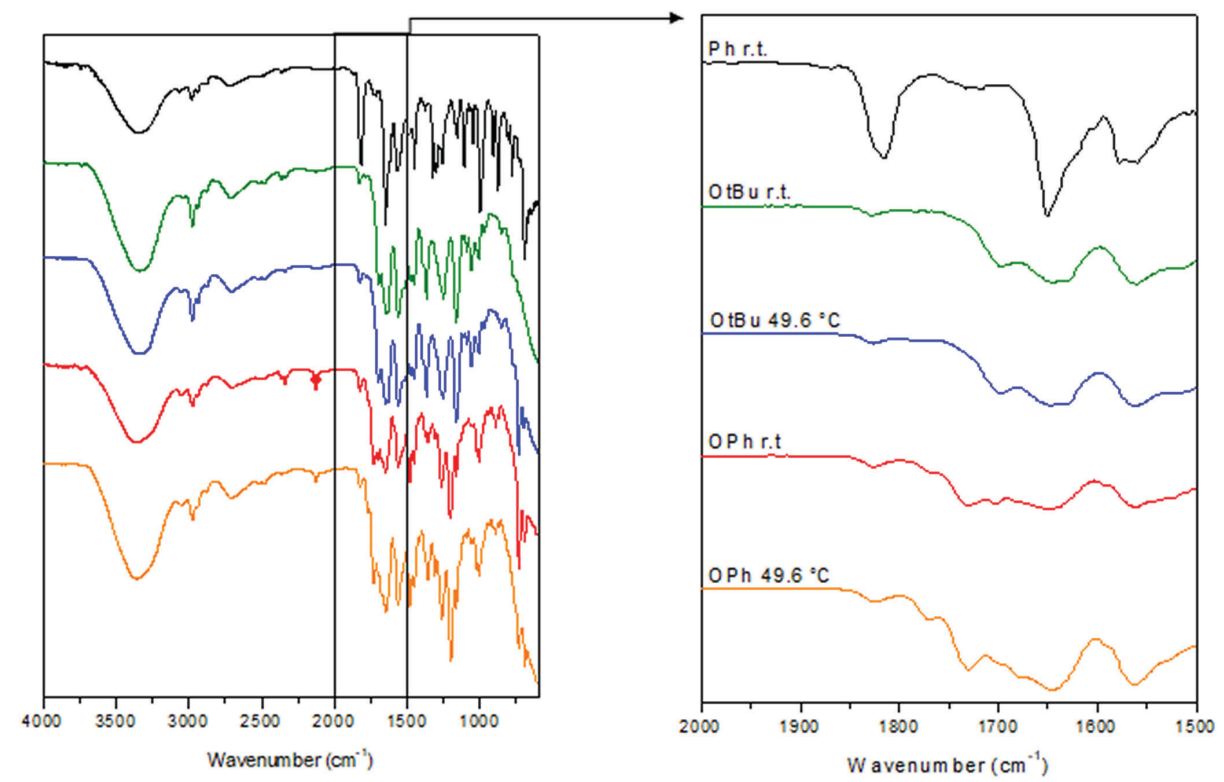

Figure 5. Reaction monitoring by IR of the crude reaction mixture of different $N$-protected amino acids in the presence of EDC (aliquots taken after $1 \mathrm{~h}$ of reaction). 


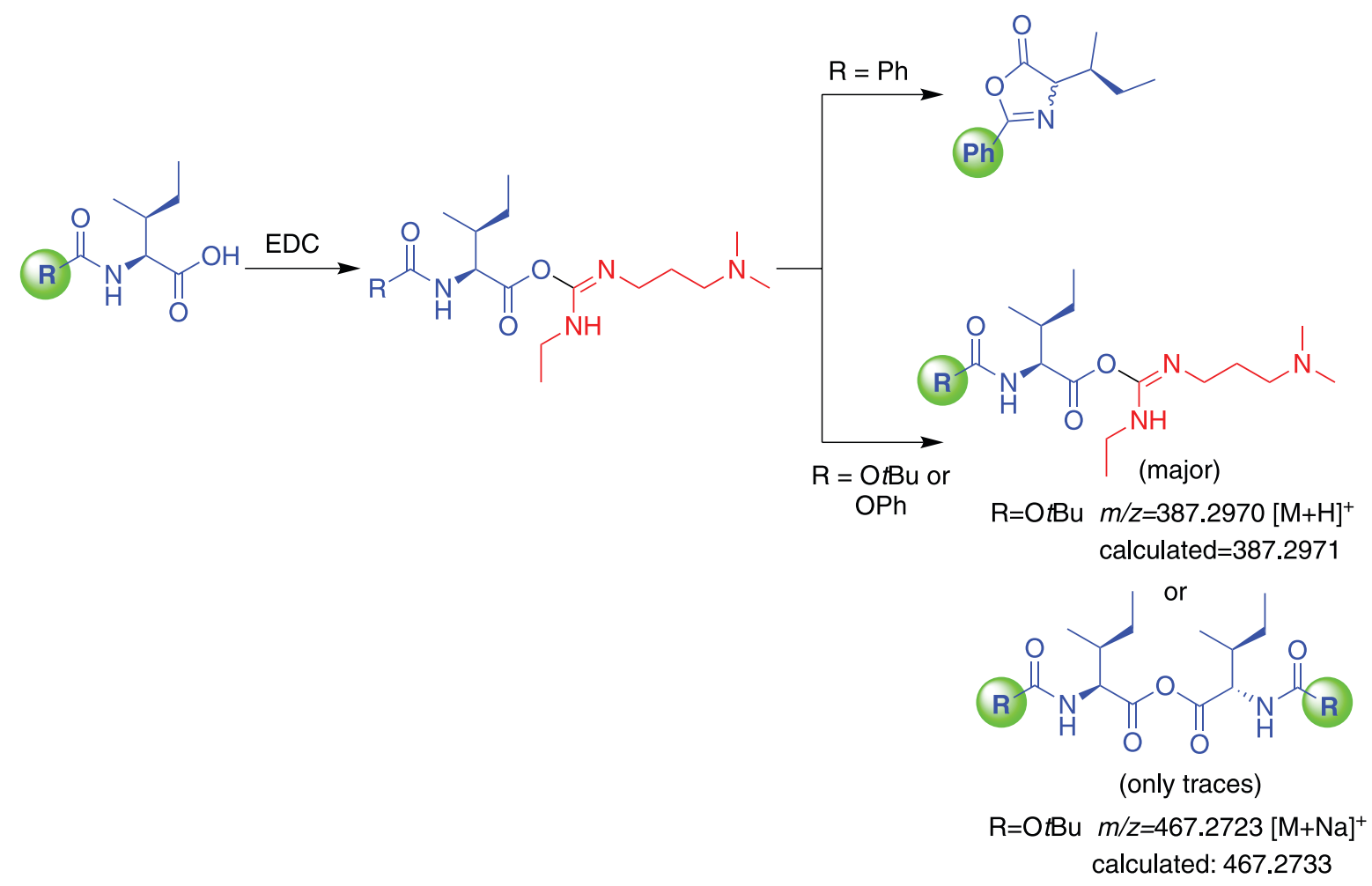

Scheme 2. Divergent behavior observed during the reaction monitoring of different $N$-protected amino acids by IR and ESI(+)-MS.

by nuclear magnetic resonance (NMR) analyses; besides, when a nucleophile was added to the reaction mixture (see reference 15), the dual-protected amino acid was isolated in up to $86 \%$ yield (if the anhydride was the only intermediate, the yield could not be higher than 50\%).

\section{Conclusions}

The study hereby reported presented the theoretical and experimental investigations on the formation of different 2-substituted azlactones. For this purpose, a density functional theory (DFT) study employing the PBE0-D3/6-31++G(d,p)//B3LYP/6-31G(d) level was carried out. According to the obtained data, the formation of 2-alcoxy azlactones is less favored both kinetically (with $\Delta \mathrm{G}^{\ddagger}$ up to $5.3 \mathrm{kcal} \mathrm{mol}^{-1}$ higher than for other 2-substituted azlactones) and thermodynamically (overall reaction $\Delta \mathrm{G}$ up to $12.2 \mathrm{kcal} \mathrm{mol}^{-1}$ higher than in other oxazolones) when compared to the alkyl of aryl substituted analogues. Besides, the activated amino acid species have a low energy conformation bearing an intramolecular hydrogen bonding in an 8-membered ring arrangement (up to $9.1 \mathrm{kcal} \mathrm{mol}^{-1}$ more stable); however, for the cyclization step to take place, a torsion of the amino acid moiety activated by EDC also seems to be necessary, playing an important role in the formation of these cycles. The substituent also has an important effect on this step, with easier attainment of the folded conformation for either 2-alkyl or 2-phenyl groups. Finally, the experimental monitoring of crude reaction mixtures by IR and ESI(+)-MS showed that a 2-phenyl azlactone is readily formed in the presence of EDC, while when $\mathrm{N}$-carbamate protected amino acid analogues are employed, none or only traces of desired azlactones were observed, in perfect accordance with the theoretical data. Therefore, in short, a combined experimental and DFT calculations were used to clarify an old drawback regarding oxazolone ring formation. Finally, these findings, certainly, will be useful for the high complex amino acid derivatives synthesis using azlactone ring approaches; furthermore, these results can also lead to the development of catalytic approaches for the 2-alcoxy azlactone preparation.

\section{Experimental}

\section{Theoretical calculations}

All calculations were performed employing the Gaussian 09 package. ${ }^{18}$ Minimum energy conformations for all species were determined in the gas phase employing DFT methodology ${ }^{19}$ with the hybrid B3LYP functional ${ }^{20}$ and $6-31 \mathrm{G}(\mathrm{d})$ basis-set. The same level of theory has also been applied to vibrational frequency calculations and Gibbs free energy prediction. Transition states (TSs) were optimized using the Berny algorithm ${ }^{21}$ or the QST2 
method, ${ }^{22}$ and confirmed to have only one imaginary frequency. All calculations were performed at pressure equal to $1 \mathrm{~atm}$ and temperature $298.15 \mathrm{~K}$, similar to the conditions usually employed in the experimental conditions for azlactone formation.

After geometry optimization, single-point energy calculations were performed in gas phase and dichloromethane using the both $\mathrm{PBE} 0^{23}$ and $\mathrm{PBE} 0-\mathrm{D} 3^{24}$ functional (to compare the extent and significance of dispersive interactions) ${ }^{25}$ with $6-31++\mathrm{G}(\mathrm{d}, \mathrm{p})$ basis set and the IEFPCM solvation model approach for dichloromethane. ${ }^{26}$ Thus, the variation of the Gibbs free energy $\left(\Delta \mathrm{G}_{\mathrm{sol}}^{\circ}\right)$ could then be obtained by the sum of the three energy contributions shown below:

$$
\Delta \mathrm{G}_{\mathrm{sol}}^{\mathrm{o}}=\Delta \mathrm{E}_{\mathrm{gas}}+\delta \Delta \mathrm{G}_{\mathrm{solv}}+\Delta \mathrm{G}_{\mathrm{T}}^{\mathrm{o}}
$$

in which the terms are, respectively, the electronic energy $\Delta \mathrm{E}_{\text {gas }}$, solvation Gibbs free energy $\left(\delta \Delta \mathrm{G}_{\text {solv }}\right.$, both found at PBE0 or PBE0-D3 theory level) and thermal correction to the enthalpy and entropy $\left(\Delta \mathrm{G}_{\mathrm{T}}^{\circ}\right.$, obtained from the B3LYP calculations).

\section{Azlactone preparation and monitoring by IR and ESI(+)-MS}

All purchased chemicals were used as received without further purification. Solvents were dried following standard procedures. The $N$-protected amino acids were prepared and purified following literature data. ${ }^{27}$ The azlactone heterocycle was prepared according to literature protocols..$^{28} \mathrm{An}$ attempt to prepare the 2-alcoxy azlactones was also carried out at $49.6^{\circ} \mathrm{C}$ (dichloromethane reflux). Aliquots from the crude reaction mixtures were taken and directly analyzed in an IR spectrometer or mass spectrometer. Infrared (IR) spectra were recorded on a PerkinElmer 1720 FTIR spectrometer by attenuated total reflectance (ATR) in the region of 4000$600 \mathrm{~cm}^{-1}$. High resolution mass spectra were investigated in the positive ion mode using a time-of-flight (TOF) mass spectrometer equipped with an ESI source.

\section{Supplementary Information}

The supplementary data (Cartesian coordinates provided for all the stationary points on the potential energy surface, copies of experimental NMR, IR and ESI(+)-MS data) are available free of charge at http://jbcs.sbq.org.br as a PDF file.

\section{Acknowledgments}

The authors acknowledge the financial support from FAPEMIG, CAPES, CNPq and Rede Mineira de Química.
H. F. D. S. also thanks FAPEMIG (CEX-APQ-00591-15) for providing support to his laboratory.

\section{References}

1. Nájera, C.; Sansano, J. M.; Chem. Rev. 2007, 107, 4584.

2. Alba, A.-N. R.; Rios, R.; Chem. - Asian J. 2011, 6, 720.

3. Pinheiro, D. L. J.; Batista, G. M. F.; de Castro, P. P.; Flores, L. S.; Andrade, G. F. S.; Amarante, G. W.; Beilstein J. Org. Chem. 2017, 13, 2663.

4. de Castro, P. P.; Carpanez, A. G.; Amarante, G. W.; Chem. - Eur. J. 2016, 22, 10294.

5. Crisma, M.; Valle, G.; Formaggio, F.; Toniolo, C.; Bagno, A.; J. Am. Chem. Soc. 1997, 119, 4136.

6. Benoiton, N. L.; Chen, F. M. F.; Chem. Biol. Drug Des. 1993, $42,455$.

7. Zhang, Y.; Muthana, S. M.; Farnsworth, D.; Ludek, O.; Adams, K.; Barchi, J. J.; Gildersleeve, J. C.; J. Am. Chem. Soc. 2012, 134, 6316.

8. Ávila, E. P.; Justo, R. M. S.; Gonçalves, V. P.; Pereira, A. A.; Diniz, R.; Amarante, G. W.; J. Org. Chem. 2015, 80, 590.

9. Pereira, A. A.; de Castro, P. P.; de Mello, A. C.; Ferreira, B. R. V.; Eberlin, M. N.; Amarante, G. W.; Tetrahedron 2014, 70, 3271.

10. Pinheiro, D. L. J.; Ávila, E. P.; Batista, G. M. F.; Amarante, G. W.; J. Org. Chem. 2017, 82, 5981.

11. Pinheiro, D. L. J.; Ávila, E. P.; Amarante, G. W.; ChemistrySelect 2016, 1, 2960.

12. Pinheiro, D. L. J.; Batista, G. M. F.; Gonçalves, J. R.; Duarte, T. N.; Amarante, G. W.; Eur. J. Org. Chem. 2016, 2016, 459.

13. Ávila, E. P.; de Mello, A. C.; Diniz, R.; Amarante, G. W.; Eur. J. Org. Chem. 2013, 2013, 1881.

14. de Castro, P. P.; Batista, G. M. F.; dos Santos, H. F.; Amarante, G. W.; ACS Omega 2018, 3, 3507.

15. de Castro, P. P.; Rimulo, I. M. R.; de Almeida, A. M.; Diniz, R.; Amarante, G. W.; ACS Omega 2017, 2, 2967.

16. dos Santos, H. F.; Vieira, M. A.; Sánhez Delgado, G. Y.; Paschoal, D.; J. Phys. Chem. A 2016, 120, 2250.

17. Sánchez Delgado, G. Y.; Paschoal, D.; dos Santos, H. F.; Comput. Theor. Chem. 2017, 1108, 86.

18. Frisch, M. J.; Trucks, G. W.; Schlegel, H. B.; Scuseria, G. E.; Robb, M. A.; Cheeseman, J. R.; Scalmani, G.; Barone, V.; Mennucci, B.; Petersson, G. A.; Nakatsuji, H.; Caricato, M.; Li, X.; Hratchian, H. P.; Izmaylov, A. F.; Bloino, J.; Zheng, G.; Sonnenberg, J. L.; Hada, M.; Ehara, M.; Toyota, K.; Fukuda, R.; Hasegawa, J.; Ishida, M.; Nakajima, T.; Honda, Y.; Kitao, O.; Nakai, H.; Vreven, T.; Montgomery Jr., J. A.; Peralta, J. E.; Ogliaro, F.; Bearpark, M.; Heyd, J. J.; Brothers, E.; Kudin, K. N.; Staroverov, V. N.; Kobayashi, R.; Normand, J.; Raghavachari, K.; Rendell, A.; Burant, J. C.; Iyengar, S. S.; Tomasi, J.; Cossi, M.; Rega, N.; Millam, J. M.; Klene, M.; 
Knox, J. E.; Cross, J. B.; Bakken, V.; Adamo, C.; Jaramillo, J.; Gomperts, R.; Stratmann, R. E.; Yazyev, O.; Austin, A. J.; Cammi, R.; Pomelli, C.; Ochterski, J. W.; Martin, R. L.; Morokuma, K.; Zakrzewski, V. G.; Voth, G. A.; Salvador, P.; Dannenberg, J. J.; Dapprich, S.; Daniels, A. D.; Farkas, Ö.; Foresman, J. B.; Ortiz, J. V.; Cioslowski, J.; Fox, D. J.; Gaussian 09, Revision D.01; Gaussian, Inc.: Wallingford, CT, 2009.

19. Parr, R. G.; Weitao, Y.; Density-Functional Theory of Atoms and Molecules; International Series of Monographs on Chemistry; Oxford University Press: Oxford, 1989.

20. Lee, C.; Yang, W.; Parr, R. G.; Phys. Rev. B 1988, 37, 785.

21. Li, X.; Frisch, M. J.; J. Chem. Theory Comput. 2006, 2, 835.

22. Peng, C.; Schlegel, H. B.; Isr. J. Chem. 1993, 33, 449.
23. Adamo, C.; Barone, V.; J. Chem. Phys. 1999, 110, 6158.

24. Grimme, S.; Antony, J.; Ehrlich, S.; Krieg, H.; J. Chem. Phys. 2010, 132, 154104.

25. Jindal, G.; Sunoj, R. B.; Angew. Chem., Int. Ed. 2014, 53, 4432.

26. Scalmani, G.; Frisch, M. J.; J. Chem. Phys. 2010, 132, 114110.

27. de Castro, P. P.; dos Santos, I. F.; Amarante, G. W.; Curr. Org. Synth. 2016, 13, 440.

28. Melhado, A. D.; Amarante, G. W.; Wang, Z. J.; Luparia, M.; Toste, F. D.; J. Am. Chem. Soc. 2011, 133, 3517.

Submitted: June 18, 2018 Published online: August 16, 2018 